\title{
Exhaust system piping made by hydroforming: relations between stresses, microstructure, mechanical properties and surface
}

\author{
Barbara Kucharska $^{1}$ (D) . Oskar Moraczyński ${ }^{1}$
}

Received: 6 March 2020 / Revised: 4 October 2020 / Accepted: 15 October 2020

(c) The Author(s) 2020

\begin{abstract}
The subject of research is car exhaust system piping made of chromium-nickel steel of grade AISI304L with a unique, complex shape that was obtained by hydroforming technology. The purpose of the research was to determine the relation between the microstructure features, surface condition, hardness and the stresses on the external surface as determined by the $\sin ^{2} \psi$ X-ray method. We found that the stresses were tensile and correlated with the steel hardness, i.e. they were greater where the hardness was higher. Moreover, longitudinal stresses showed a relationship with pipe wall thickness, while circumferential stresses did so only partially. According to our data, the greatest value of stress determined in the pipe amounted to $290 \mathrm{MPa}$, and was close to the yield point of the strain hardened 304L steel. As depicted via XRD and SEM examination, the pipe stress level and hardness were influenced by the transition $\gamma \rightarrow \alpha$ '. Furthermore, in the region of higher stress and hardness, the amount of martensite was $10 \mathrm{vol} . \%$. We also noted that the pipe's outer surface when subjected to friction against the die shows lesser roughness compared to its inner surface upon exposure to water under pressure.
\end{abstract}

Keywords X-ray stress measurements $\cdot$ Stainless steels $\cdot$ Hydroforming $\cdot$ TRIP phenomenon

\section{Introduction}

Challenges faced by the automotive industry relate not only to the issues of vehicle safety and exhaust gas emission reduction, but also to the enhancement of vehicle users' comfort, e.g. by enlarging the cabin and luggage part spaces. A design objective becomes, therefore, to pack the mechanical parts within the smallest possible space. In addition to their functional function, those parts must also have complex shapes. These, in turn, even using the most known and developed plastic forming operations, are often only possible to be achieved by several-stage bending, pressing, etc. [1], and welding of a few smaller components. Making the whole complex-shape part is enabled by the hydroforming technology $[2,3]$.

Barbara Kucharska

barbara.kucharska@pcz.pl

Oskar Moraczyński

oskar.moraczynski@pcz.pl

1 Faculty of Production Engineering and Materials Technology, Czestochowa University of Technology, Armii Krajowej 19, 42-200 Czestochowa, Poland
In hydroforming technology, a pressurized liquid (water or oil) is used for forming products [4]. Shaping flat and tubular metal sheet products by the above-mentioned technology is in common use [5]. Examples of the most known hydroformed products are bicycle frames and many cars components, such as the carrying frames, car bodies, engine cradles and mufflers [6]. The greatest interest is currently focused on forming variable closed profiles, especially with diverse diameters/radii and their derivations [7] (Fig. 1). The automotive industry is presently the largest recipient of closed-profile hydroformed products, followed by the aviation and aerospace industries $[8,9]$.

The advantages of the method in question include reduction of the number of welded joints in structures and of the amount of special equipment, as well as obtaining parts with thinner walls, better dimensional tolerance and surface condition [10-13]. The disadvantage of this forming method is slow production cycle and high cost of tools.

Although hydroforming technology has been known for about 30 years, the applications of hydroformed tubular components have significantly increased in the last ten years. The reasons for this are more advanced pressing control technology, and the availability of FEM-which supports the design of the tools and components $[14,15]$. However, 
(a)

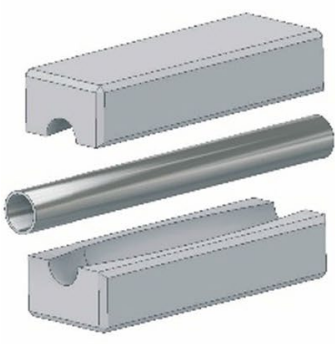

(b)

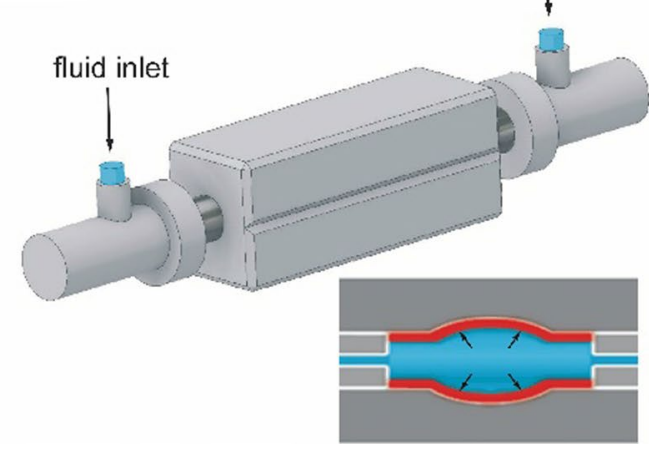

(c)

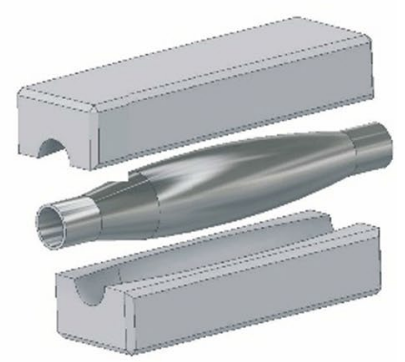

Fig. 1 Scheme of the hydroforming operation: placing the pipe in the die (a), sealing the pipe ends, introducing a fluid inside the pipe and forming the pipe shape under fluid pressure (b), discharging the fluid and removing the formed part out from the die (c)

real product control tests are still necessary to ensure the optimization of production technology [16], and the intent of these is to gather as much experimental data as possible to allow adequate modelling of the production process [17].

In the automotive industry, products of aluminium, stainless steels and DP, TRIP and TWIP steels are manufactured by this method so as to obtain the added value of reduced energy intensity at fast deformation [18]. The capability to reduce the mass of parts and to obtain better properties fully offsets the higher cost of those metals, compared to using deep drawing steels [19].

Austenitic stainless steels for exhaust systems are currently preferred to the use of ferritic steels (aluminiumcoated $[20,21])$, due to the better plastic formability of the former [22]. Stainless austenitic steels from the so-called 300 series according to ASTM, include a wide group of steel containing min. $10.5 \%$ masses $\mathrm{Cr}$ and min. $8 \%$ masses $\mathrm{Ni}$. Such steels have an extremely favourable combination of chemical properties, such as resistance to corrosion and oxidation, as well as good mechanical and plastic forming capabilities [23]. The global consumption and production of these steels is still at a high level, with a growing trend currently of almost 6\%/year [24]. It should be noted that $95 \%$ of the total austenitic stainless steel production is used in creating plastically shaped products, of which almost $10 \%$ finds application in the automotive industry.

One of the technological problems of the plastic shaping of these steels (especially by hydroforming) is the transformation of austenite into martensite [25, 26]. This causes structural inhomogeneity within the steel products [27]. Complex deformation conditions, the shape and structure can result in a heterogeneous and varied stress distribution in the hydroformed product. Hence, after a longer period of operation, items, such as exhaust pipes, can be deformed as a result of vibrations and variable temperature of the flue gas and the environment. In this work, pipes made via hydroforming technology were thoroughly tested for the level and distribution of surface stresses, hardness, wall thickness, roughness and microstructure. Because the actual experimental data concerning mechanical and surface condition of a pipe are necessary to design a product or verify the generated numerical models, the purpose of the research was to ascertain the relation between these properties, with particular emphasis on the determination of their influence on the tested pipe's surface stresses.

\section{Materials and research methodology}

The subject of research was automobile exhaust system piping (connecting pipe in Fig. 2a) made of chromium-nickel steel in grade AISI304L (X5CrNi18-10) (Table 1). This steel has lower carbon content and enhanced nickel content compared to the basic grade AISI304. This formula favours the stabilization of austenite and better plastic deformability. The pipe, approx. $1 \mathrm{~m}$ long, has a complex shape obtained by hydroforming technology (Fig. 2b).

The objective of the research was to determine the mechanical properties of the pipe, such as residual stress and hardness, as well as its microstructure and wall thickness reduction. For the purposes of testing, four regions (perimeters) were sectioned off on the pipe, of which three (denoted as B, C and D-Fig. 2b) were situated in the locations of great change in pipe shape, while one (denoted as A-Fig. 2b), near the pipe end was where the pipe cross section was the closest in shape to circular.

On each perimeter, 4 points $(1,2,3,4)$ positioned every $\sim 90^{\circ}$ are indicated, whereby a total of 16 stress measurement points are obtained: A1-A4, B1-B4, C1-C4 and D1-D4. Points marked with the same number, e.g. 1, are situated along one pipe generating line. 


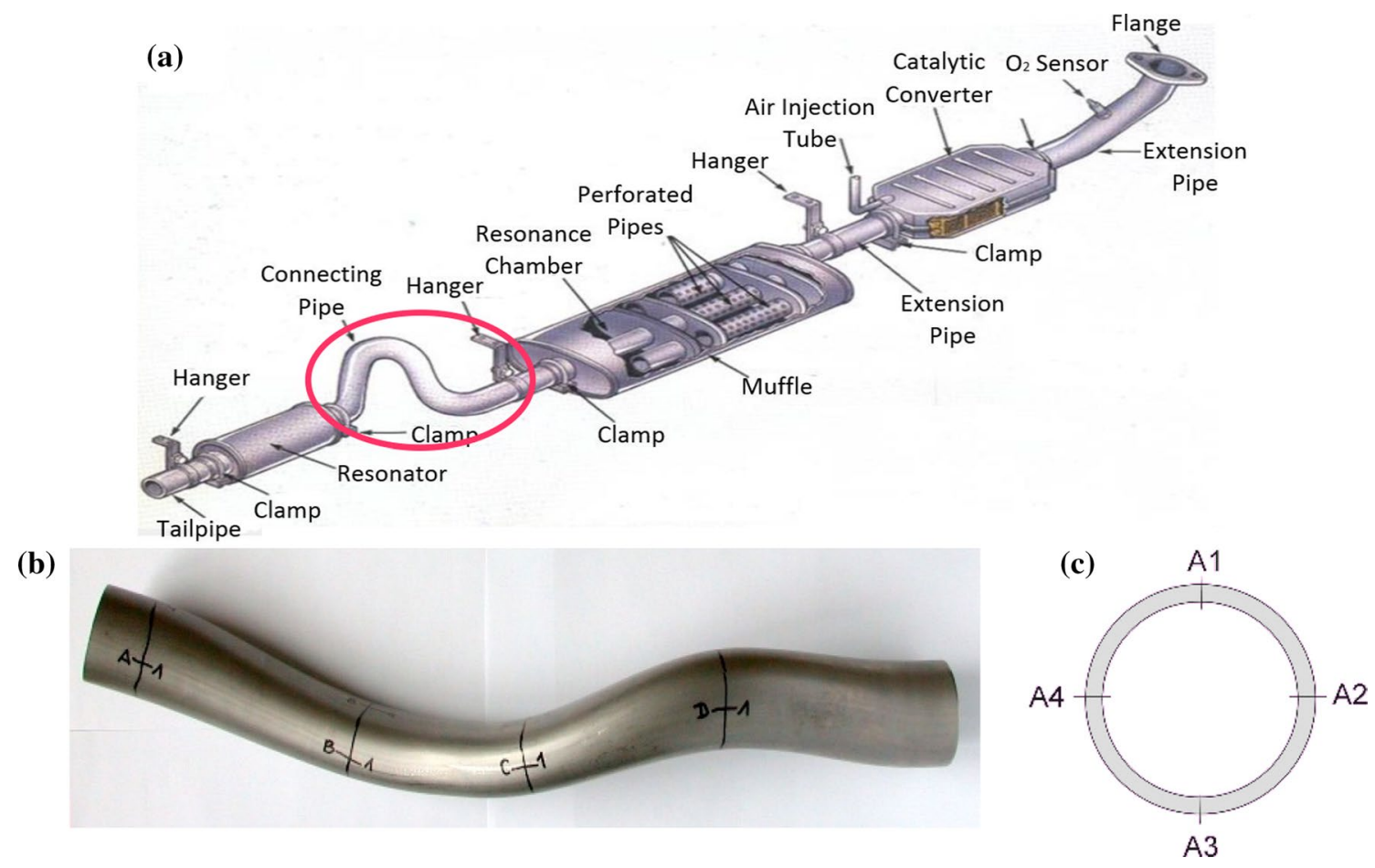

Fig. 2 The hydroformed pipe under investigation: (a) location in the exhaust system [32], (b, c) general view with scheme of stress measurement and hardness testing points indicated on length and perimeter of the pipe

Table 1 Chemical composition of investigated pipe, wt $\%$

\begin{tabular}{lllllllllllllll}
\hline $\mathrm{C}$ & $\mathrm{Si}$ & $\mathrm{Mn}$ & $\mathrm{Cr}$ & $\mathrm{Ni}$ & $\mathrm{P}$ & $\mathrm{S}$ & $\mathrm{Co}$ & $\mathrm{Mo}$ & $\mathrm{Cu}$ & $\mathrm{Nb}$ & $\mathrm{V}$ & $\mathrm{W}$ & Other & $\mathrm{Fe}$ \\
\hline 0.039 & 0.40 & 1.40 & 18.21 & 9.59 & 0.033 & 0.005 & 0.20 & 0.04 & 0.70 & 0.02 & 0.07 & 0.06 & $<0.04$ & $\sim 68.3$ \\
\hline
\end{tabular}

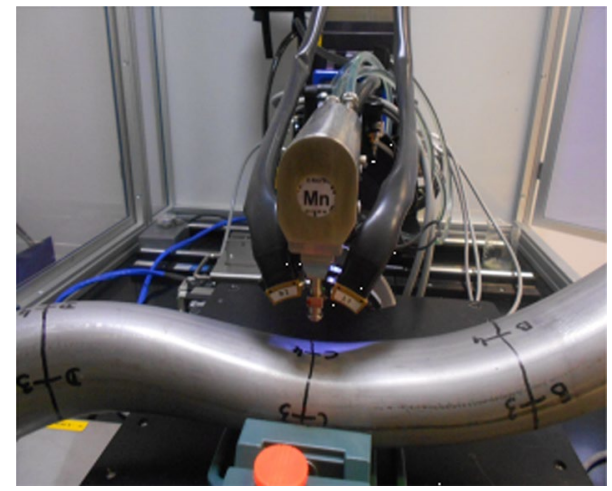

Fig. 3 Stress measurement at $\mathrm{C} 4$ point on pipe surface using an X-ray diffractometer

Surface stresses in the pipe were determined using X-ray PROTO equipped with two detectors (Fig. 3). The $\mathrm{K}_{\alpha} \mathrm{Mn}$ radiation of a wavelength of $0.21030 \mathrm{~nm}$ and the $\sin ^{2} \psi$ method procedure were used.

The X-ray method allows for determining the residual stresses remaining in the polycrystalline material after previous technological operations. In the case of the investigated pipe, this came about after plastic working process that caused deformation of the lattice, $\varepsilon$ expressed with the change of inter-planar distances, $\Delta d$, in relation to the distances in the stress-free material $d_{o}\left(\varepsilon=\Delta d / d_{o}\right)$ [28]. In the $\sin ^{2} \psi$ method, stress $\sigma_{\phi}$ is determined in a specific direction of the tested product. Direction of stress is defined by $\phi$ angle, usually selected by the positioning of the part during measurement (under laboratory conditions). The relationship between lattice deformation $\varepsilon$ and stress $\sigma_{\phi}$ in $\sin ^{2} \psi$ is described by formula (1).

$\varepsilon_{\phi \psi}=\Delta d / d_{o}=((1+v) / E) \sigma_{\phi} \sin ^{2} \psi+(v / E)\left(\sigma_{11}+\sigma_{22}\right)$

where $\nu$-Poisson's ratio, E-Young's modulus, $\sigma_{11}$ and $\sigma_{22}$-principal stresses in the part surface plane.

The graphic representation of Eq. (1) shown in Fig. 4a elucidates the possibility of estimating the $\sigma_{\phi}$ stress from the slope of the straight line drawn based on the first term of the equation, without having to know the values of principal stress in the material region under examination. In practice, this is possible by determining the interplanar distances 
(a)

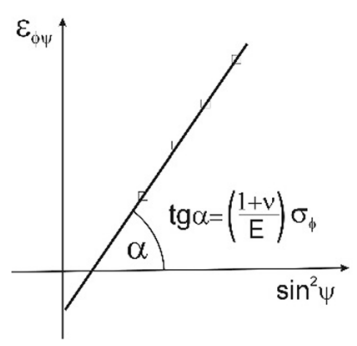

(b)

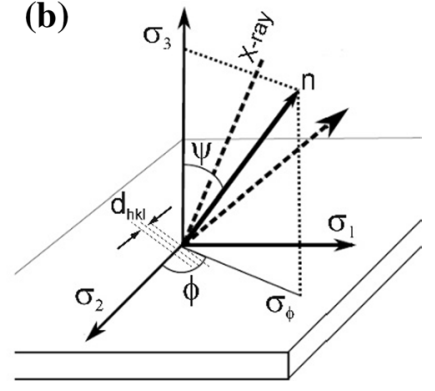

Fig. 4 The $\sin ^{2} \psi$ method: stress determination from X-ray measurement data (a) and schematic diagram of measurement geometry (b), were: $\sigma_{1}, \sigma_{2}$ and $\sigma_{3}-$ axes of the laboratory system usually associated with the shape of the detail (sample), $\mathrm{n}$ - diffraction vector

when tilting the examined part surface (or the diffractometer head) relative to the diffraction vector by different angles $\psi$ (Fig. 4b). In this work, $\psi$ angle varied in the range $<-40^{\circ}$, $40^{\circ}>$.

The pipe circumferential and longitudinal stresses determined in the study are based on the diffraction reflection, $\mathrm{hkl}=311$; the Young's modulus, $\mathrm{E}=167 \mathrm{GPa}$; and Poisson's ratio, $v=0.2$ (state of max softened steel). For determining the phase composition of steel, a Seifert diffractometer and $\mathrm{K}_{\alpha}$ Co radiation of a wavelength of $0.17903 \mathrm{~nm}$ were used.

Hardness tests were performed by the Vickers method, under the load of $3 \mathrm{~kg}(29.43 \mathrm{~N})$, on the outer surface of specimens taken from the pipe, each of a size of approx. $50 \times 70 \mathrm{~mm}$. The specimens taken from the pipe were additionally used for the examination of the pipe surface condition (morphology by SEM JSM-6610LV and topography by profilometer Hommel measurements over the length of $4.8 \mathrm{~mm}$ ), pipe wall thickness measurements (micrometer) and for making metallographic microsections and performing steel microstructure observations.

\section{Investigation results and discussion}

\subsection{Surface stresses}

Sample X-ray measurement results as the relationship of the interplanar distances $d_{311}$ as a function of $\sin ^{2} \psi$ are shown in Fig. 5.

The values of the calculated stresses, circumferential $\sigma_{\mathrm{c}}$ and longitudinal $\sigma_{1}$, at all pipe outer surface points are illustrated schematically in Fig. 6. All of the determined stresses were tensile stresses. These stresses differed in value both along the pipe length, as well as on the pipe perimeter.

The most diverse circumferential stresses $(26 \div 290 \mathrm{MPa})$ were in region $\mathrm{C}$, that is the one on which the average value was the smallest (122 MPa). In other regions, especially B and D, stresses were higher (aver. $\sigma_{\mathrm{c}}=203$ and $189 \mathrm{MPa}$ ) and less diversified (max. $\Delta \sigma=69 \mathrm{MPa}$ )—Figs. 6a and 7 . As far as longitudinal stresses are concerned, for region A, their average magnitude was at a level similar to that of the circumferential stresses (aver. $\sigma_{1}=170 \mathrm{MPa}$ ). In regions B and $\mathrm{D}$, longitudinal stresses were smaller (aver. $\sigma_{\mathrm{c}}=154$ and $118 \mathrm{MPa}$ ), while in region $\mathrm{C}$, such stresses were higher (aver. $\sigma_{1}=143 \mathrm{MPa}$-Figs. $6 \mathrm{~b}$ and 7.

The range and average values of the determined surface stresses were compared with the numerical model for the formed pipe that were obtained from the manufacturer and graphically presented in an earlier work [29]. According to the model, the pipe was subjected to the largest deformations in the end regions (region A) while affected by the smallest deformations in the middle part (region C). Moreover, in region $\mathrm{C}$, the average magnitudes of surface stresses, determined in both directions $\left(\sigma_{c}\right.$, as well as $\left.\sigma_{1}\right)$, were the smallest.

It should be noted that the stress magnitudes determined within by the X-ray $\sin ^{2} \psi$ method with $\mathrm{K}_{\alpha} \mathrm{Mn}$ wavelength refer to the steel's surface layer of a max thickness of approx. $0.17 \mu \mathrm{m}$. Stresses in even thinner surface layers can be determined using the $g-\sin ^{2} \psi(G X R D)$ method [30]. In case of computer modelling of large, actual products, deformations are usually analysed in thicker layers of the material.

\subsection{Stresses vs thickness of the wall and hardness}

The degree of pipe steel deformation represented in the model can be, in practice, expressed by the measurement of pipe wall thickness and hardness in individual pipe regions. The results of the measurement of both of these parameters are illustrated in the diagrams in Fig. 8. On account of the surface curvature and the small wall thickness, direct hardness testing of the pipe could be performed only in a limited range. Therefore, hardness measurements (HV3) were performed on the surfaces of specimens taken from the pipe. As follows from the comparison, hardness tests reflected changes in wall thickness values, that is, the hardness was smaller when the wall thickness was greater.

This means that in the region $\mathrm{A}$ and $\mathrm{B}$, where the pipe wall had the smallest thickness, the steel had undergone the heaviest plastic deformation, and thus also strain hardening. The hardness values in both of these regions were comparable, in spite of differences in pipe wall thickness.

An attempt to relate the determined stress values with the pipe wall thickness in individual pipe regions revealed some deviations from the presumed rule stating that larger stresses should be expected in the locations of the smallest wall thickness (Fig. 9). Nevertheless, it can be noticed that this relationship does occur for longitudinal stresses. In the case of multiple circumferential stresses, their magnitudes deviate from the above-mentioned relationship. In both stress cases, the most deviating and the largest are stresses 
(a)

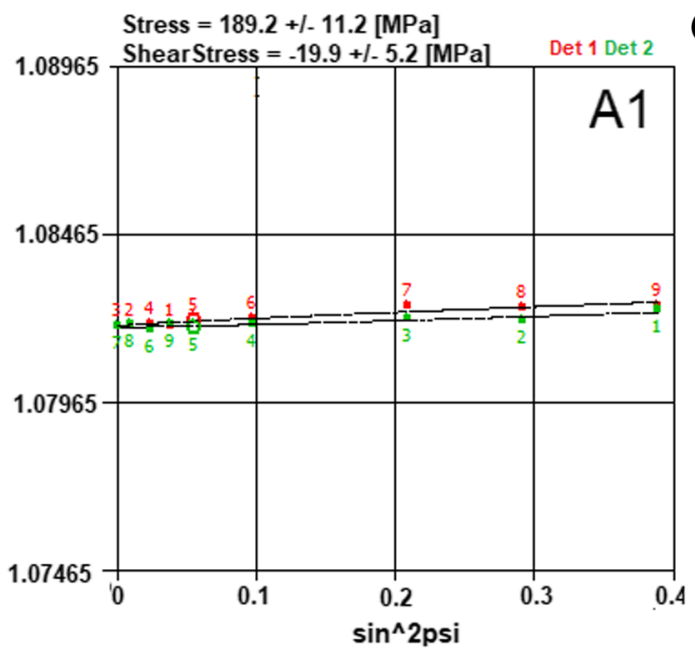

(c)

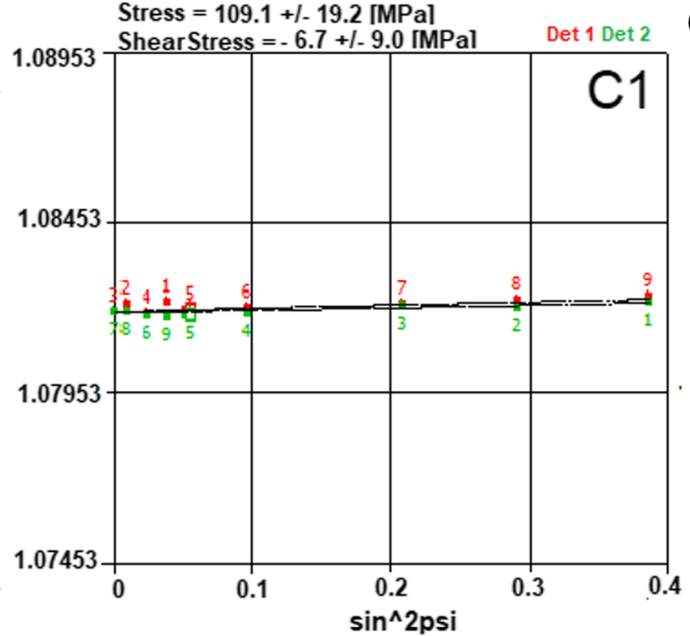

(b)

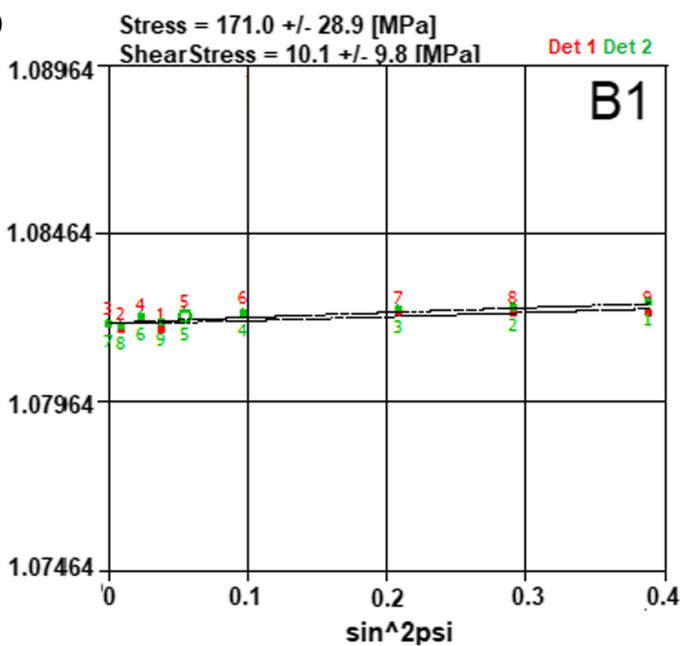

(d)

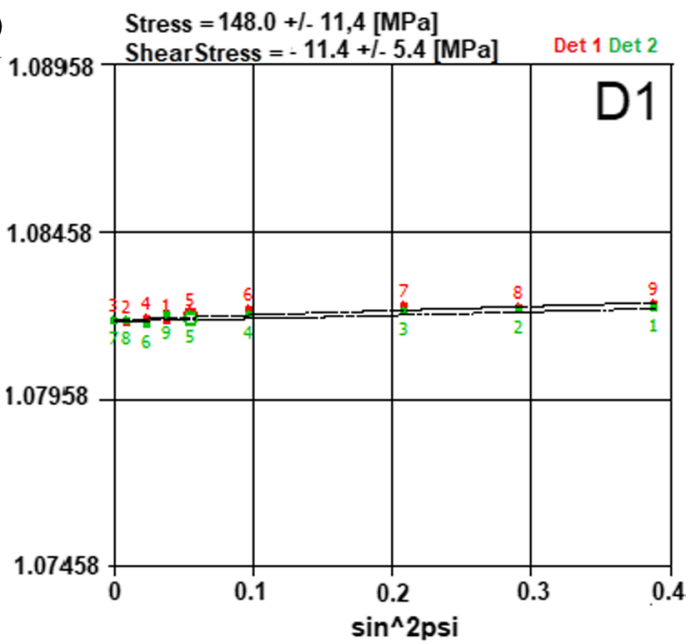

Fig. 5 Example results of the determination the interplanar distances, $\mathrm{d}_{311}$ as a function of $\sin ^{2} \psi$, at points A1 (a), B1 (b), C1 (c) and D1 (d) on outer tube surface

Fig. 6 Stress distribution on the pipe outer surface: circumferential (a), longitudinal (b). Symbols: A, B, C and D - pipe perimeters, 1, 2, 3 and $4-$ points at perimeters situated every $90^{\circ}$ (a)

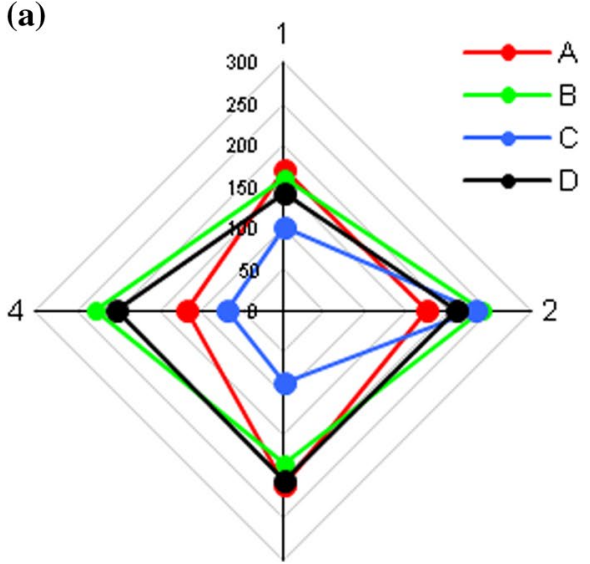

3

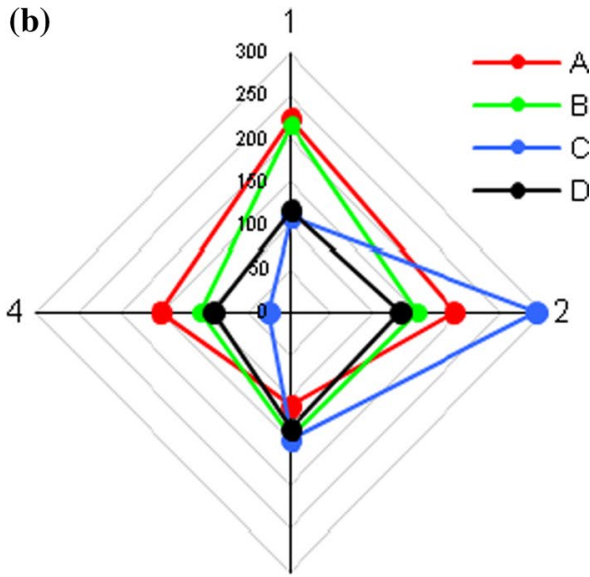

3 


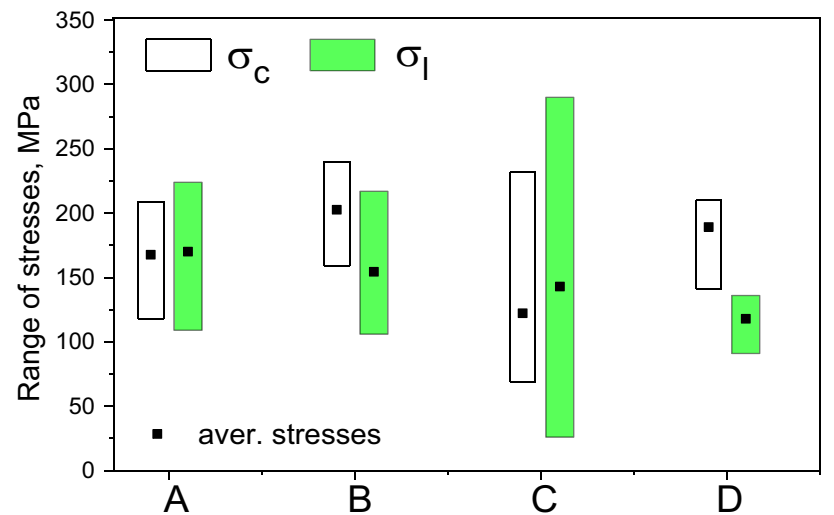

Fig. 7 A comparison of the range and average values of stresses on the pipe's surface $(\mathbf{c})$. The stress estimation errors were contained within the range of 34-40 MPa. Symbols: A, B, C and D - pipe perimeters

at point C2 (indicated in Fig. 9). To verify that the magnitudes of stresses in this region are not due to a measurement error, measurement was made in another laboratory on the same type of diffractometer. An identical stress distribution in region $\mathrm{C}$ was obtained.

More clearly than when considering the wall thickness, relating of the determined stress values with pipe hardness in individual pipe regions (Fig. 10) points out the relationship that greater stresses can be found in pipe regions where the pipe hardness is higher. Herein, we must take into account the fact that the hardness was determined on sections taken out from the pipe and it can be presumed that a change in stress state occurred as a result of cutting due to partial stress relaxation. Hence, as can be seen, the state of stress in the pipe was related to the microstructure in individual pipe regions, which had not changed due to stress relaxation. This general rule of hardness and stress relationship, as expressed in Fig. 11, therefore, does not always find confirmation in the detailed analysis of stress distribution.
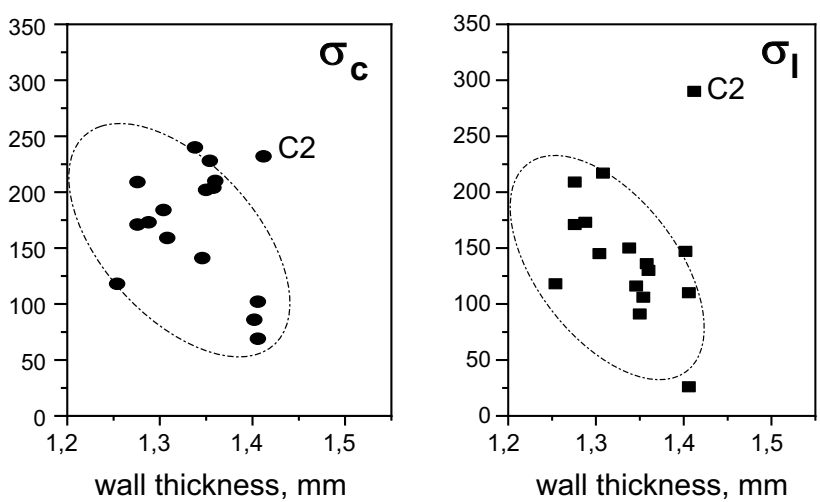

Fig. 9 The stress values determined on the pipe surface as dependent on wall thickness
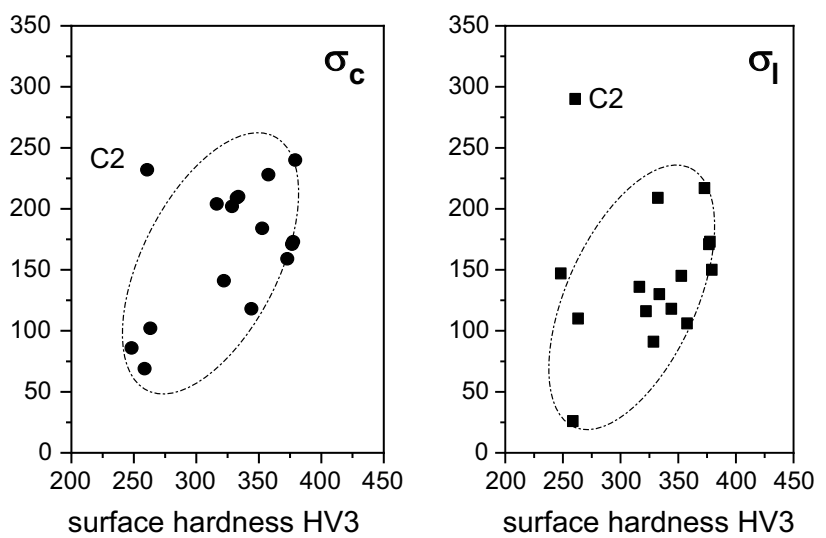

Fig. 10 The stress values determined on the pipe surface as dependent on surface hardness. Point $\mathrm{C} 2$ is indicated separately

Figure 11 illustrates the relative distribution of the determined stresses and hardness across the pipe length. It shows that, whereas the hardness varies across the pipe length following the same pattern regardless of the pipe generating
Fig. 8 Wall thickness (a) and surface hardness (b) in different pipe regions

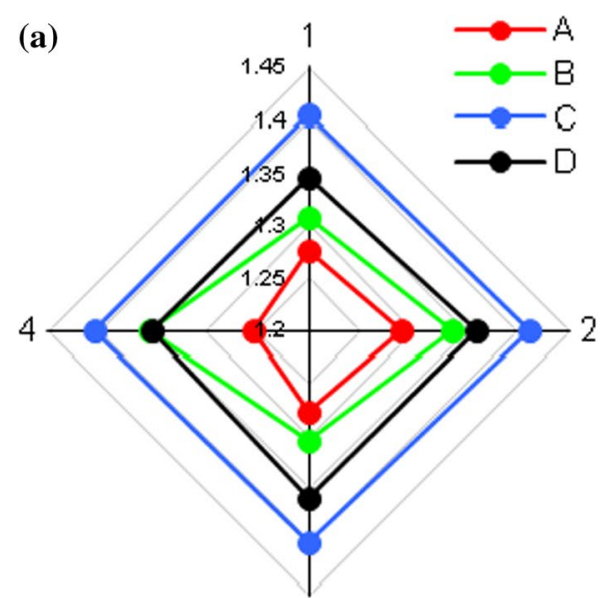

3

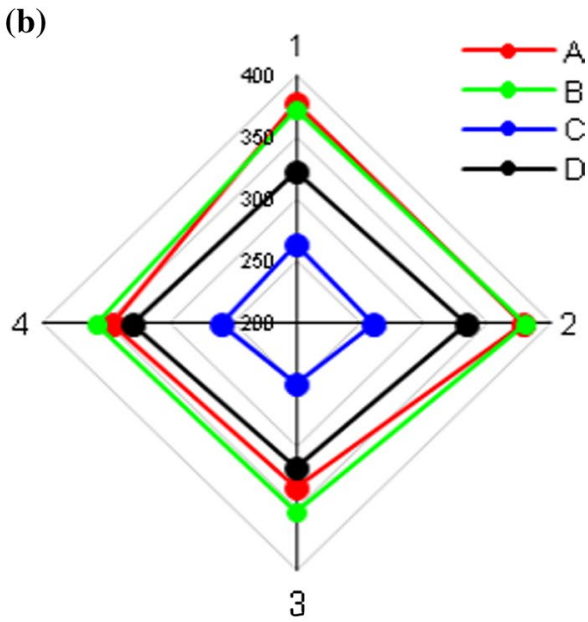



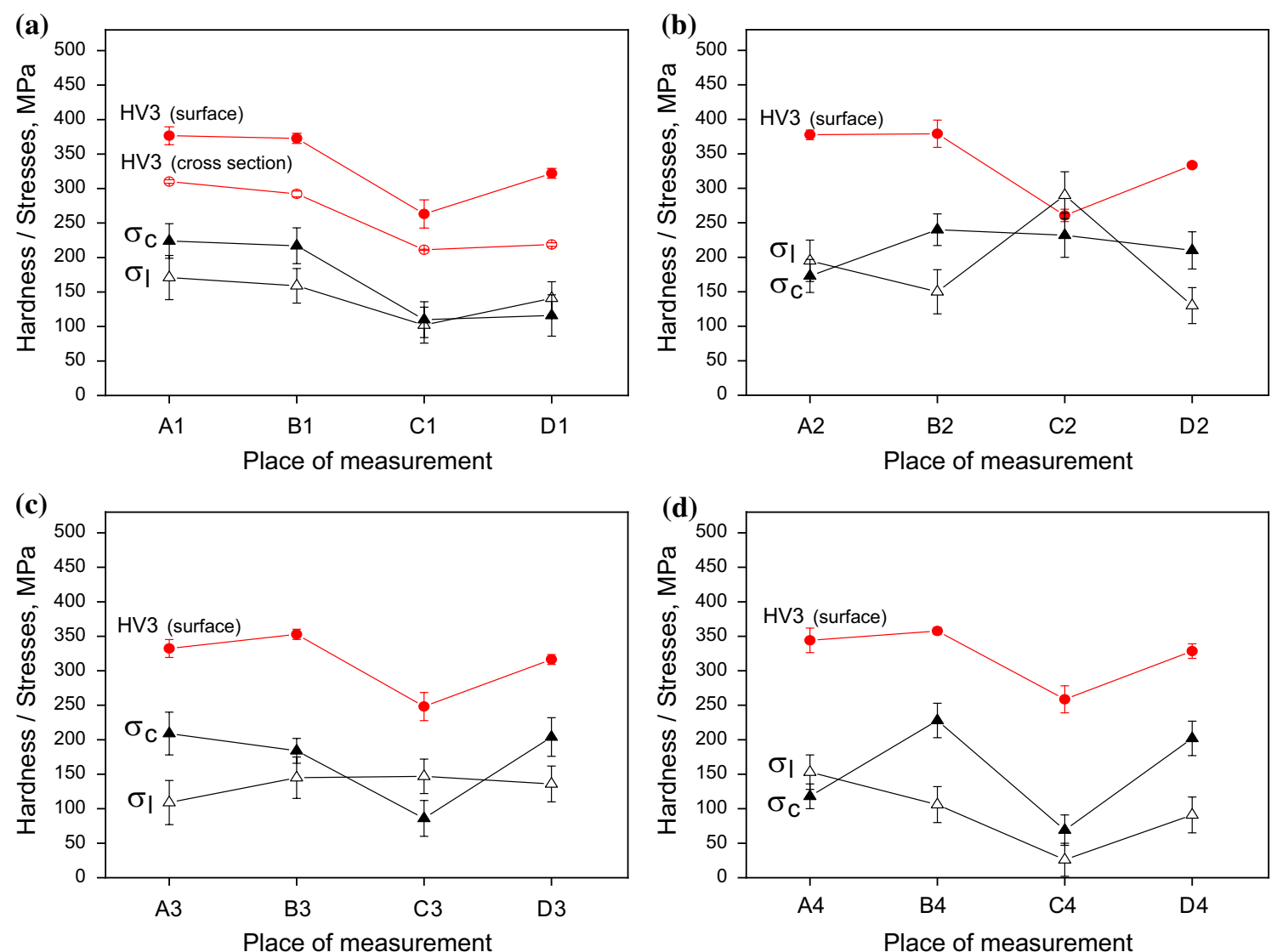

Fig. 11 Hardness and stresses on the pipe outer surface - distribution on the pipe length, on the generating line 1 (a), 2 (b), 3 (c) and 4 (d)

line under consideration, the stresses are distributed in a more complex manner. The hardness values represent the distribution of the stresses $\sigma_{\mathrm{c}}$ and $\sigma_{1}$ only along generating line 1 and the stresses $\sigma_{\mathrm{c}}$ along generating line 3. On generating line 4 , the stress distribution is similar in character to the hardness distribution, while on generating line 2 , there is no correlation whatever between hardness and stresses. Thus, the determined hardness reflected mainly the condition of the steel microstructure than the actual stresses in the pipe before cutting.

\subsection{Pipe microstructure}

Steel X5CrNi18-10, of which the pipe was made, belongs to the group of heat-resisting steels of series 300 (AISI) with an austenitic structure. Numerous slip lines and deformation twins still occurred in the steel within austenite grains, as the consequence of its plastic forming. In region A1 with the most reduced wall thickness, the number of slip bands within grains was estimated as greater than in region $\mathrm{C} 1$ with the greatest wall thickness (Figs. 12 and 13). Therefore,
Fig. 12 Microstructure of hydroformed pipe in region $\mathrm{A} 1$ on longitudinal (a) and on transverse section (b) (etched in aq. solution of $\mathrm{HNO}_{3}$ and $\mathrm{NH}_{4} \mathrm{~F}$ )
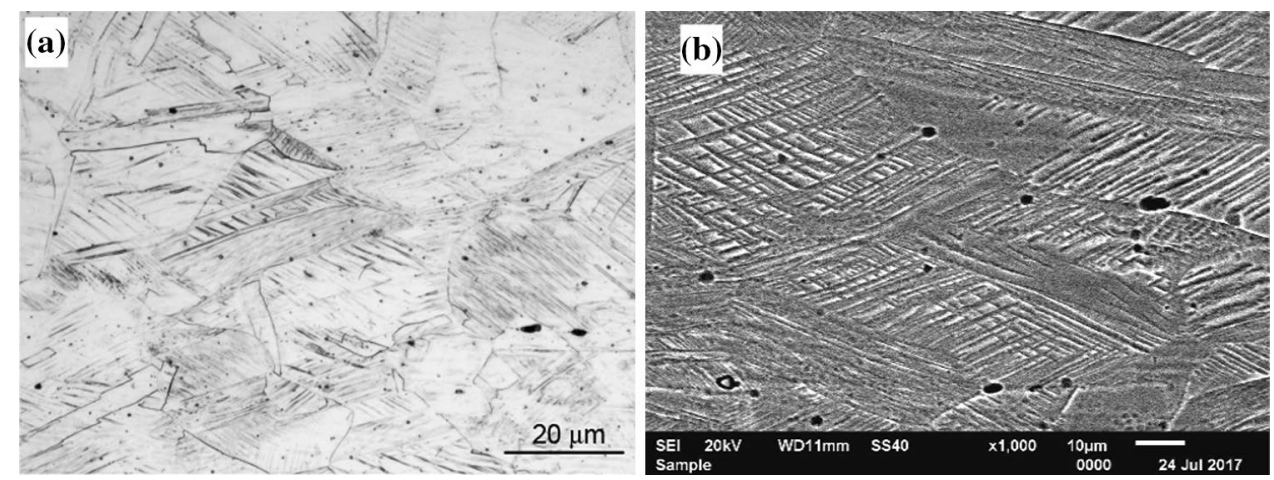
Fig. 13 Microstructure of hydroformed pipe in region $\mathrm{C} 1$ on longitudinal (a) and on transverse section (b) (etched in aq. solution of $\mathrm{HNO}_{3}$ and $\mathrm{NH}_{4} \mathrm{~F}$ )
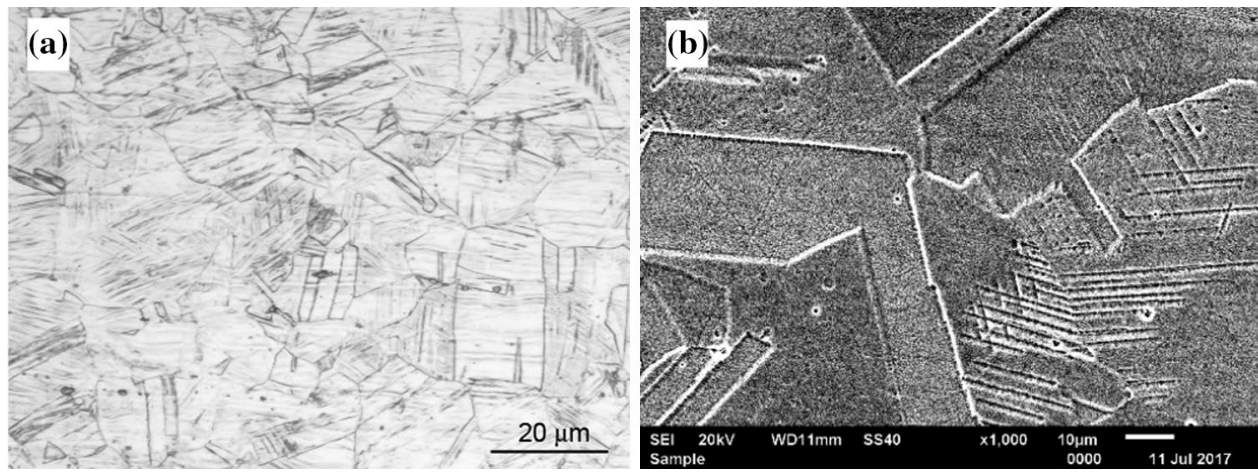

the hardness of steel in region C1 was the lowest (263/211 HV3).

The diffraction measurements confirmed the different state of the steel in the region $\mathrm{A} 1$ and $\mathrm{C} 1$ of the pipe. The differences in the surface state concerned the texture and phase composition of the steel (Fig. 14). In the region A1, a most clear texture of the planes (220) was found (Fig. 14a). Such a texture is formed in AISI304 grade steel during its strong tensile strain. An example of a steel stress-strain curve and a diffraction pattern of the broken steel with this texture is shown in Fig. 15. In the region C1, the steel texture was weaker and the mutual relations of the diffraction intensity were more similar to those in the austenite standard PDF4 + [31] (Fig. 16).

The diffractograms additionally show that the steel in both tested areas of the pipe marked $\mathrm{A} 1$ and $\mathrm{C} 1$, transformed into martensite during the forming. The percentage of martensite was estimated at about $10 \mathrm{vol} \%$ in the area of A1 and about 4 vol.\% in the area of $\mathrm{C} 1$. For comparison, in the same steel deformed in the tensile test up to rupture, more than $40 \mathrm{~V} \%$ martensite was formed as a result of the phase transformation. If we assume that in the 304L steel the transformation $\gamma \rightarrow \alpha$ ' proceeds in a straight relationship to elongation $(>0,2 \%)$, this deformation of steel in the A1 area of pipe would correspond to approx. $18 \%$ of elongation, and in the $\mathrm{C} 1$ area, to approximately $7 \%$ of elongation. This is roughly that much as the wall thickness reduction was in these regions. The formed martensite causes an additional increase in steel hardness above the level resulting from the strain hardening of the austenite.

\subsection{Surface of the pipe}

The specificity of pipe forming by the hydroforming method is the absence of mechanical friction on the inner surface of the pipe. Only the outer pipe surface undergoes mechanical friction against the die. In our sample, this was macroscopically reflected by both the presence of streaks of technological tarnish on the surface, as well as a general surface smoothing (Fig. 17a, b), which were not observed on the inner surface (Fig. 17c, d). A pipe surface roughness measurement showed that the value of $R_{a}$ for the outer surface
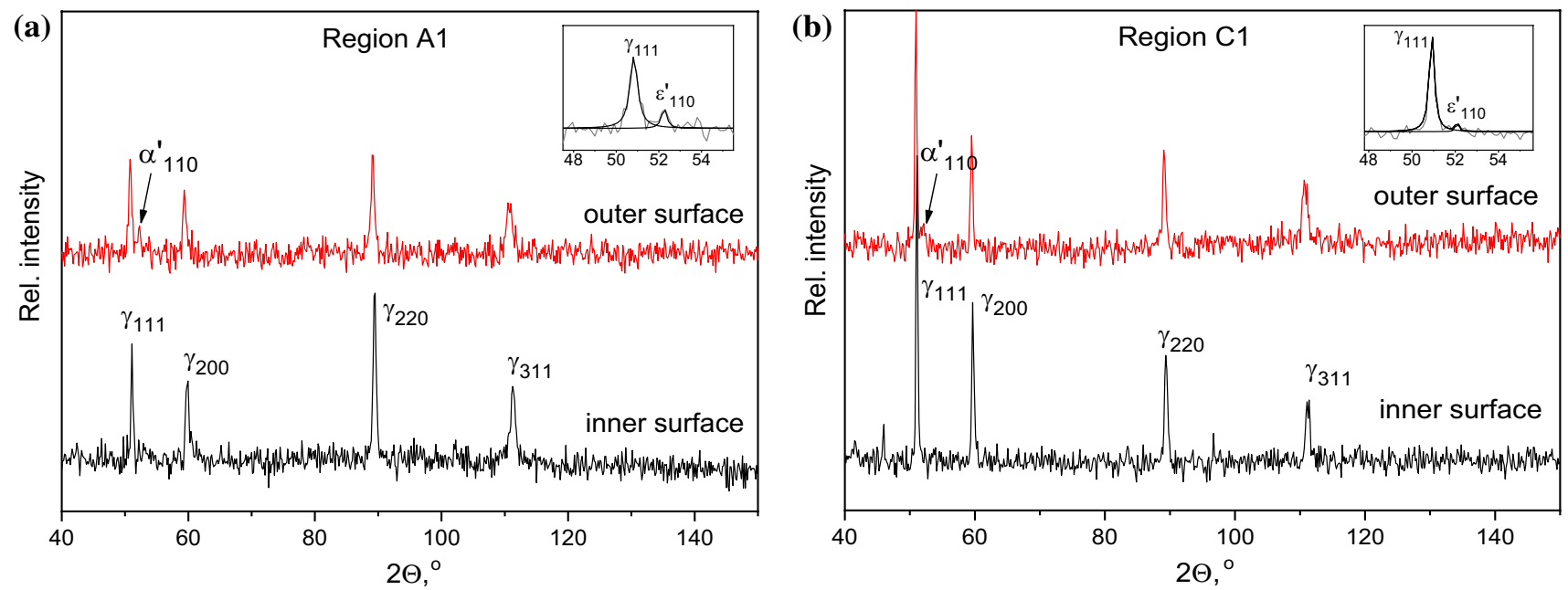

Fig. 14 Diffractograms of the outer and inner surface of the pipe in A1 region (a) and in C1 region (b) 
(a)

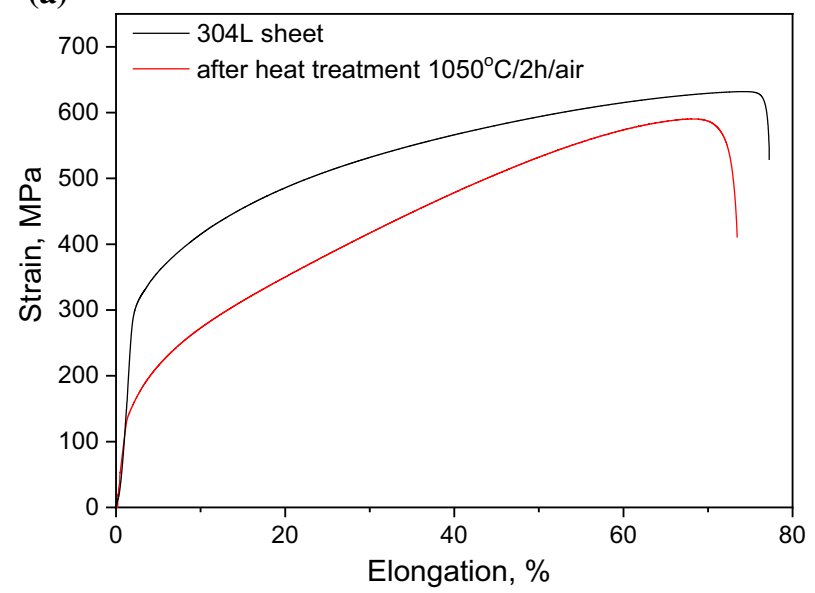

(b)

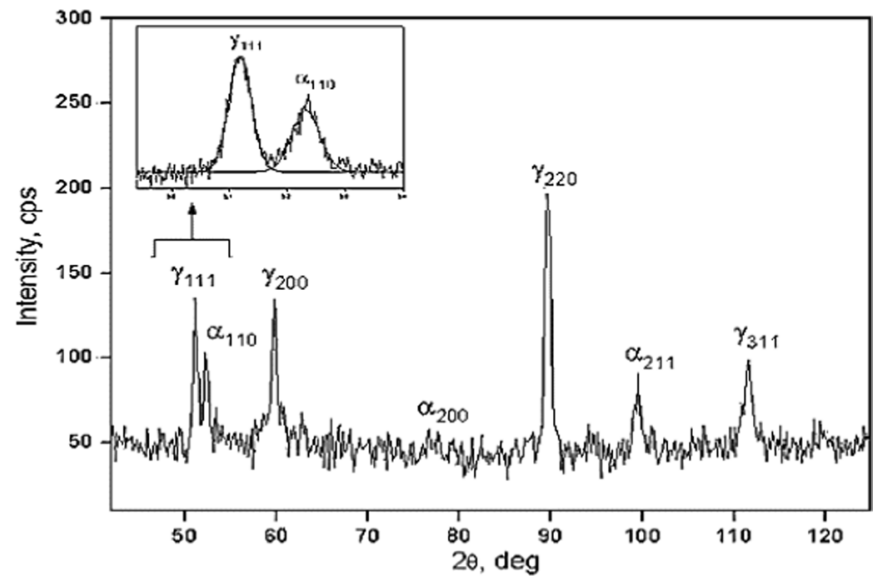

Fig. 15 Stress-strain curves of steel 304L (a) and the diffraction pattern of the heat-treated steel after tensile test (b)

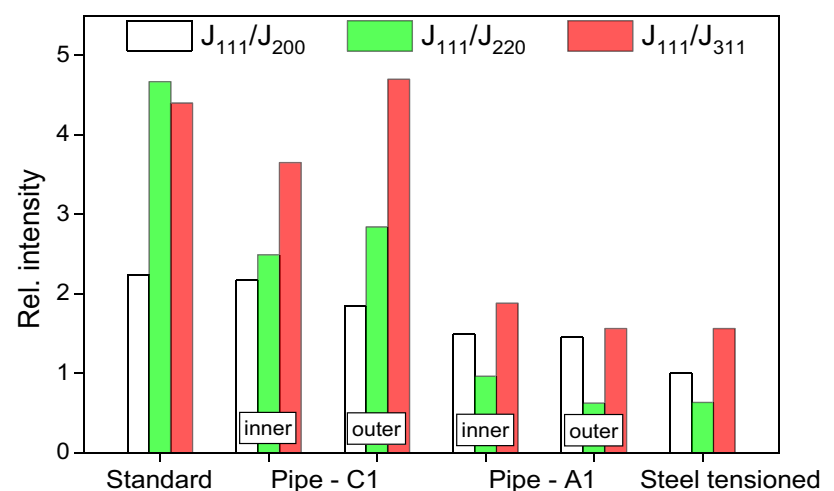

Fig. 16 Relationships of intensity of diffraction reflections in the tested steel and reference standards

was, on average, 2 times smaller compared to the $R_{a}$ value for the inner surface (Fig. 18).

\section{Discussion and conclusion}

The article has presented an example of a closed-section part, an exhaust system pipe, whose unique, complex shapes is achievable only thanks to the use of hydroforming technology. The complex, asymmetric deformation of the pipe involved the formation of a complex state of stress within it. Such a part (pipe) has no free edges at which partial plastic material can flow, and thus where partial stress reduction could take place. Therefore, tensile stress, sharply varying in magnitude, may under operation conditions cause dimensional changes in the part.

- In the investigated exhaust system pipe formed by hydroforming technology, an inhomogeneous distribution of circumferential and longitudinal stresses was found. Stresses differed in value both along the pipe length, as well as on the pipe perimeter. The stress values generally correlated with the steel hardness in respective regions, i.e. they were greater where the hardness was higher. Longitudinal stresses showed a relationship with pipe wall thickness (opposite than with hardness), while circumferential stresses did so only partially. The largest deviations from the expected relationships occurred in pipe region $\mathrm{C}$ (on the perimeter, in the central pipe part), which was characterized by relatively the smallest wall thickness reduction, determined both from the authors' own measurements and from numerical modelling. In that region, the scatter of stress values was the greatest, i.e. both the smallest and the largest of the stresses determined in the pipe occurred there.

- The greatest value of stress determined in the pipe, amounting to $290 \mathrm{MPa}$, is close to the yield point of the strain hardened 304L steel. The location of that critical stress occurring in the pipe $(\mathrm{C} 2)$ is potentially the most burdened with the risk of deformation or damage during pipe operation.

- The pipe stress level and wall hardness are influenced by the microstructure of steel $304 \mathrm{~L}$, where the transition $\gamma \rightarrow \alpha$ ' occurs under the influence of deformation (the TRIP phenomenon). Our work indicates that the degree of transition is higher in the region of higher stress and hardness. Whence it follows that the stress in the pipe, and more specifically in the austenite phase, is a result of the joint effect of the degree of deformation of the austenite lattice and the share of martensite in the structure due to the TRIP phenomenon.

- Hydroforming technology features a unilateral lack of part friction against the dies; so, in the case of the pipe under investigation, its inner surface would only come 
Fig. 17 The state of the outer pipe surface in region A2 (a) and in region $\mathrm{D} 2$ (b) and the inner surface in region $\mathrm{C} 2(\mathbf{c})$ and in region $\mathrm{B} 2(\mathbf{d})$
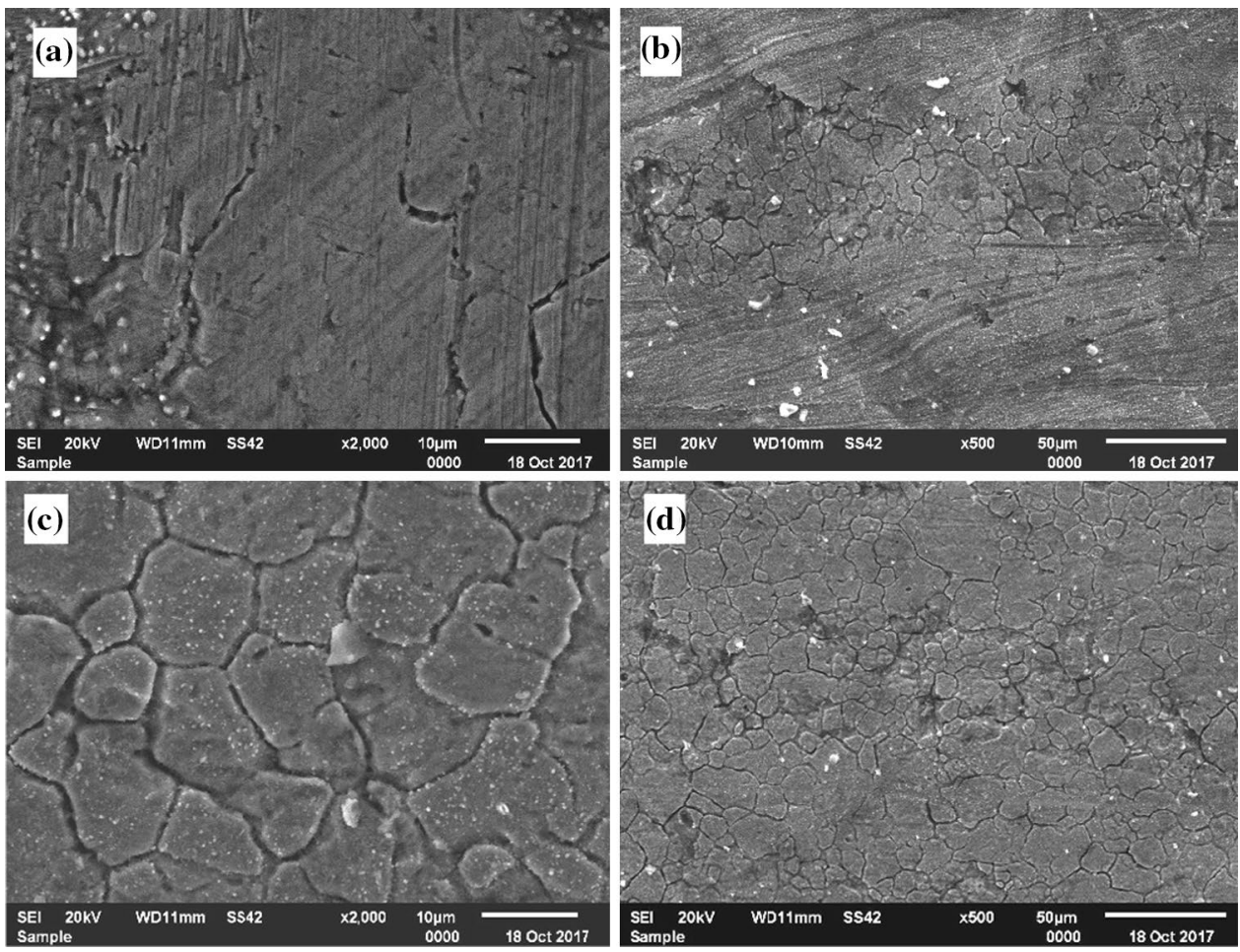

into contact with the liquid. An increased wall thinning in hydroformed parts occurs usually in the corners of closed sections, especially when a maximally high liquid pressure is applied with the aim of accurately reproducing the called-for dimensions and shape. In the investigated pipe, in spite of the absence of corners, the pipe wall was unevenly thinned. This indicates the influence of the conditions of pipe outer surface friction against the die on the local wall thickness and, as a consequence, on the surface stress level. Of note, the outer pipe surface,

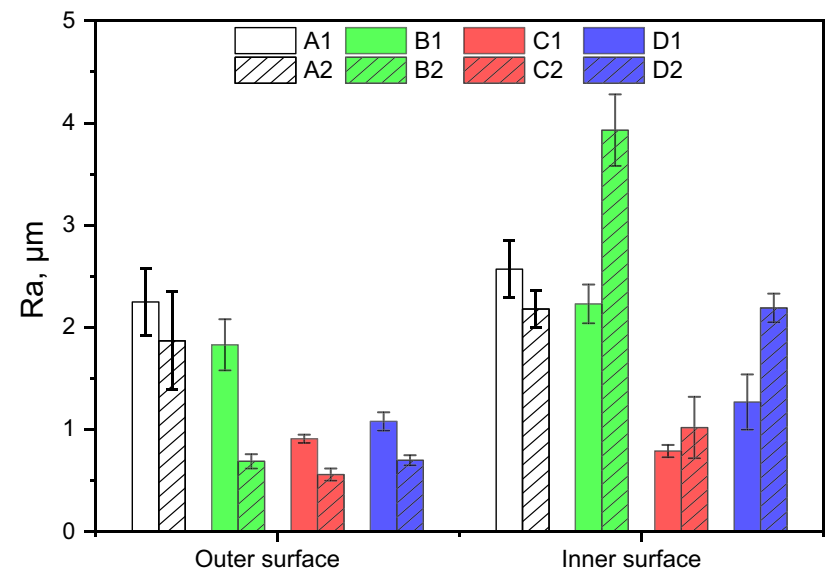

Fig. 18 The roughness of the outer and inner pipe surfaces, respectively, in different pipe regions although subjected to friction, shows a lesser roughness compared to the inner surface.

- Measurement of stresses using the X-ray $\sin ^{2} \psi$ method is a very useful tool for practical and non-destructive evaluation of various factors - both technological and operational-on the state of surface stresses in hydroformed products. It is possible to directly determine, for example, the influence of the degree of plastic deformation, lubricant supply and microstructure in the execution technology, but also to generate awareness of any possible operating incidental phenomena (associated e.g. with transport and storage), which could occur in production conditions.

Acknowledgements The authors would like to thank Dr. Eng. D. Dyja from Tenneco Automotive Polska Sp. z o. o. (Rybnik Engineering Center) for providing a pipe for testing.

Open Access This article is licensed under a Creative Commons Attribution 4.0 International License, which permits use, sharing, adaptation, distribution and reproduction in any medium or format, as long as you give appropriate credit to the original author(s) and the source, provide a link to the Creative Commons licence, and indicate if changes were made. The images or other third party material in this article are included in the article's Creative Commons licence, unless indicated otherwise in a credit line to the material. If material is not included in the article's Creative Commons licence and your intended use is not permitted by statutory regulation or exceeds the permitted use, you will need to obtain permission directly from the copyright holder. To view a copy of this licence, visit http://creativecommons.org/licenses/by/4.0/. 


\section{References}

1. Gronostajski Z, Pater Z, Madej L, Gontarz A, Lisiecki L, Lukaszek-Solek A, Luksza J, Mróz S, Muskalski Z, Muzykiewicz W, Pietrzyk M, Śliwa RE, Tomczak J, Wiewiórowska S, Winiarski G, Zasadziński J, Ziólkiewicz S. Recent development trends in metal forming. Archiv Civ Mech Eng. 2019;19:898-941. https:// doi.org/10.1016/j.acme.2019.04.005.

2. Koç M (Ed.), Hydroforming for Advanced Manufacturing, Woodhead Publishing Limited, England, and CRC Press, USA, 2008.

3. Bell C, Corney J, Zuelli N, Savings D. A state of the art review of hydroforming technology. Its applications, research areas, history, and future in manufacturing. Int J Mater Form. 2019. https://doi. org/10.1007/s12289-019-01507-1.

4. Koç M. An overall review of tube hydroforming (THF) technology. J Mater Process Tech. 2001;108:384-93. https://doi. org/10.1016/S0924-0136(00)00830-X.

5. Lang LH, Wang ZR, Kang DC, Yuan SJ, Zhang SH, Danckert J, Nielsen KB. Hydroforming highlights: sheet hydroforming and tube hydroforming. J Mater Process Tech. 2004;151(1-3):165-77. https://doi.org/10.1016/j.jmatprotec.2004.04.032.

6. Kocańda A, Sadłowska H. Automotive component development by means of hydroforming. Archiv Civ Mech Eng. 2008;8(3):5569. https://doi.org/10.1016/S1644-9665(12)60163-0.

7. Alaswad A, Benyounis KY, Olabi AG. Tube hydroforming process: a reference guide. Mater Des. 2012;33:328-39. https://doi. org/10.1016/j.matdes.2011.07.052.

8. Tolazzi M. Hydroforming applications in automotive: a review. Int J Mater Form. 2010;3:307-10. https://doi.org/10.1007/s1228 9-010-0768-2.

9. Lihui L, Tao L, Dongyang A, Cailou C, Danckert J. Investigation into hydromechanical deep drawing of aluminium alloyComplicated components in aircraft manufacturing. Mater Sci Eng A. 2009;499(1-2):320-4. https://doi.org/10.1016/j. msea.2007.11.126.

10. Chałupczak J, Miłek T. Hydromechanical expansion of oblique fitting from pipes. Rudy i Metale Nieżelazne. 2006;51(11):654-9 ((in Polish))

11. Miłek T. The wall thickness distributions in longitudinal sections hydromechanically bulged axisymmetric components made from cooper cross joints. J Achiev Mater Manuf Eng 2014;65:20-25. jamme.acmsse.h2.pl/vol65_1/6513.

12. Cheng DM, Teng BG, Guo B, Yuan SJ. Thickness distribution of hydroformed Y-shape tube. Mater Sci Eng A. 2009;499(1-2):369. https://doi.org/10.1016/j.msea.2007.09.100.

13. Morphy G. Pressure-sequence and high pressure hydroforming: Knowing the processes can mean boosting profits. Tube Pipe J September/October 1998 (thefabricator.com, February 2001).

14. Nico L, Dinesh KR, Rahul V, Manikandan G, Arunansu H. Tube hydroforming in automotive applications, Tata Steel, (tatasteeleurope.com 28.01.2020).

15. Mun-Young L, Sung-Man S, Chang-Young K, Sang-Yong L. Study in the hydroforming process for automobile radiator support members. J Mater Process Tech. 2002;2002:115-20. https:// doi.org/10.1016/S0924-0136(02)00749-5.

16. Elie-dit-cosaque X, Said CM, Naceur H, Gakwaya A. Analysis and design of hydroformed thin-walled tubes using enhanced one-step method. Int J Adv Manuf Tech. 2012;59:507-20. https ://doi.org/10.1007/s00170-011-3539-4.

17. Thanakijkasem P, Pattaranqkun A, Mahabunphachai S, Uthaisanqsuk V, Chutima S. Comparative study of finite element analysis in tube hydroforming of stainless steel 304. Int J Automot Tech. 2015;16:611-7. https://doi.org/10.1007/s12239-015-0062-x.

18. Bahman K. Trends for stainless steel tube in automotive applications. Tube Pipe J. September 13, 2005 (thefabricator.com).

19. Gronostajski Z, Kuziak R. Metallurgical, technological and functional foundations of advanced high-strength steels for the automotive industry. Works of the Institute of Ferrous Metallurgy, pp 22-26 (2010) (in Polish).

20. Wróbel-Knysak A, Kucharska B, Nitkiewicz Z, Lacki P. The susceptibility of AlSi coating to deep drawing (in Polish). Hutnik Wiadomości Hutnicze. 2012;79(2):943-5.

21. Kucharska B, Wróbel A, Kulej E, Nitkiewicz Z. The X-ray measurement of the thermal expansibility of Al-Si alloy in the form of cast and a protective coating on steel. Sol St Phen. 2010;163:28690. https://doi.org/10.4028/www.scientific.net/SSP.163.286.

22. Ikpe AE, Orhorhoro EK, Gobir A. Engineering material selection for automotive exhaust systems using CES software. IJET 2017;3(2):50-60. https://doi.org/10.19072/ijet.282847.

23. Xianfeng C, Zhongqi Y, Bo H, Shuhui L, Zhongqin L. A theoreti$\mathrm{cal}$ and experimental study on forming limit diagram for a seamed tube hydroforming. J Mater Process Tech. 2011;211(12):2012-21. https://doi.org/10.1016/j.jmatprotec.2011.06.023.

24. ISSF International Stainless Steels Forum. Stainless Steel Consumption Forecast, October 2017, (http://www.worldstainless.org/ statistics 12.09.2019).

25. Angel T. Formation of martensite in austenitic stainless steels: Effect of deformation, temperature and composition. J Iron Steel I. $1954 ; 177: 165-74$.

26. Das A, Chakraborti PC, Tarafder S, Bhadeshia HKDH. Analysis of deformation induced martensitic transformation in stainless steels. Mater Sci Tech. 2011;27(1):366-70. https://doi. org/10.1179/026708310X12668415534008.

27. Blicharski M, Gorczyca S. Structural inhomogeneity of deformed austenitic stainless steel. Met Sci. 1978;23:303-12.

28. Noyan C, Cohen JB. Residual stress. New York: Springer Science and Business Media; 1987.

29. Kucharska B. Identification of surface stress in the exhaust system pipe made by hydroforming technology based on diffractometric measurements. Eksploat Niezawodn 2019;21(4): 562-566. https ://doi.org/10.17531/ein.2019.4.4.

30. Wyckoff RWG, Cubic closed packed ccp structure, Crystal Structures 1 (1963) 7-83, Crystallographic Open Database (COD) \#90-900-8470.

31. Skrzypek SJ, Baczmański A. Progress in X-ray diffraction of residual macro-stresses determination related to surface layer gradients and anisotropy. Adv X Ray Anal. 2001;44:134-45.

32. Precision Automotive Service, Exhaust system, (precisionautomobileservice.com, 25.09.2019)

Publisher's Note Springer Nature remains neutral with regard to jurisdictional claims in published maps and institutional affiliations. 